\title{
Evaluation of sludge reduction of three metabolic uncouplers in laboratory-scale anaerobic-anoxic-oxic process
}

\author{
Ping $\mathrm{Li}^{\mathrm{a}}$, Hechao $\mathrm{Li}^{\mathrm{b}}$, Jin $\mathrm{Li}^{\mathrm{c}}$, Xuesong Guo ${ }^{\mathrm{c}}$, Junxin Liu ${ }^{\mathrm{c}}$, Benyi Xiao ${ }^{\mathrm{c}, *}$ \\ ${ }^{a}$ School of Environmental Science and Engineering, Guangdong University of Technology, Guangzhou 510006, China \\ ${ }^{\mathrm{b}}$ Shenzhen Ocean Power Industrial Co., Ltd, Shenzhen 518040, China \\ ${ }^{\mathrm{c}}$ Research Center for Eco-Environmental Sciences, Chinese Academy of Sciences, Beijing 100085, China
}

\section{H I G H L I G H T S}

- Effects of three metabolic uncouplers were evaluated in lab-scale A2O process.

- Differences on sludge reduction of three metabolic uncouplers was slight.

- Three uncouplers slightly lowered wastewater treatment efficiencies about 1.1-8.7\%.

- Three uncouplers increased sludge SVI about 69.9-80.6\%.

- Possible sludge reduction mechanisms of three metabolic uncouplers were different.

\section{A R T I C L E I N F O}

\section{Article history:}

Received 15 July 2016

Received in revised form 2 September 2016

Accepted 3 September 2016

Available online 7 September 2016

\section{Keywords:}

Evaluation

Metabolic uncouplers

Sludge reduction

Sludge reduction mechanism

Wastewater treatment efficiency

\begin{abstract}
A B S T R A C T
To evaluate the sludge reduction of three metabolic uncouplers $\left(3,3^{\prime}, 4^{\prime}, 5\right.$-tetrachlorosalicylanilide (TCS), 2,4-dichlorophenol (DCP), and tetrakis (hydroxymethyl) phosphonium sulfate (THPS)), we conducted continuous experiments on laboratory-scale anaerobic-anoxic-oxic processes. The three metabolic uncouplers were separately added in each oxic tank of the three systems, and a system without uncoupler addition was used as control. During the 85-day operation, sludge production and observed growth yields decreased to $38.6 \%$ and $16.98 \%, 43.4 \%$ and $17.55 \%$, and $39.3 \%$ and $17.04 \%$ by the addition of TCS, DCP, and THPS, respectively. The addition of metabolic uncouplers slightly reduced the wastewater treatment efficiencies of the system (about 1.1-8.7\%) and increased sludge SVIs (about 69.9-80.6\%). Meanwhile, the differences among three metabolic uncouplers were little. Besides metabolic uncoupling and maintenance metabolism, which exist in the TCS- and DCP-added systems, lysis-cryptic growth also exists in the THPS-added system.
\end{abstract}

(c) 2016 Elsevier Ltd. All rights reserved.

\section{Introduction}

Sewage sludge is an undesired by-product of wastewater treatment, which needs to be treated, and otherwise, may have a significant environmental impact (Li et al. 2015; Guo et al. 2013; Semblante et al. 2016). In Europe, the annual production of sewage sludge accounted for more than 10 million tons in 2010 and is expected to increase to 13 million tons in 2020 (Paul and Debellefontaine, 2007). Currently, the amount of dewatered sludge in China was over $3.0 \times 10^{7}$ tons (with $80 \%$ water content) (Zhang et al. 2016). With stricter environmental regulations and increasing wastewater quantity, the production of sewage sludge is expected to continuously increase (Guo et al. 2014b). Owing to the large volume and high cost of sludge treatment and disposal, the

\footnotetext{
* Corresponding author.

E-mail address: byxiao@rcees.ac.cn (B. Xiao).
}

production of sludge has become a serious issue for numerous wastewater treatment plants (WWTPs) worldwide (Cho et al. 2012; Guo et al. 2013; Niu et al. 2016). Therefore, sludge production in biological wastewater treatment processes should be reduced.

In sludge reduction technologies, the metabolic uncoupler addition method has attracted considerable research interest because of its convenience, high efficiency, ease of operation, and lack of required modification of conventional wastewater treatment processes or installation of expensive facilities (Guo et al. 2013; Feng et al. 2014; Tian et al. 2013). Unlike sludge pretreatment or sludge disintegration (like thermal-chemical hydrolysis) in lysiscryptic growth, which kill and lysis sludge microbial cell (Banu et al. 2009; Raj et al. 2013), metabolic uncoupler only partially uncouple the catabolism from anabolism in microbial cell which leads to reduced growth yield, while maintaining the substrate utilization rate and does not dead to cell death. Numerous metabolic 
uncouplers have been studied, including 2,4-dichlorophenol (DCP) (Chen et al. 2006), 3,3',4',5-tetrachlorosalicylanilide (TCS) (Aragóna et al. 2009; Feng et al. 2014), 2,4-dinitrophenol (dNP) (Chen et al. 2008), gramicidin (Strand et al. 1999), and 2,4,6-trichlorophenol (TCP) (Feng et al. 2013; Zheng et al. 2008). Some of these metabolic uncouplers exhibited good efficiency in sludge reduction. For example, Fang et al. (2015) found that sludge was reduced to $58.2 \%, 59.8 \%$, and $80.8 \%$, respectively, by the addition of $20 \mathrm{mg} / \mathrm{L}$ pCP, oCP, and oNP in a batch experiment. Meanwhile, Feng et al. (2014) obtained $42.7 \%$ reduction of the observed growth yield $\left(Y_{\text {obs }}\right)$ of sludge with the addition of $1.0 \mathrm{mg} / \mathrm{L} \mathrm{TCS}$.

In some previous studies (Guo et al. 2014b; Xiao et al. 2016), researchers found that tetrakis hydroxymethyl phosphonium sulfate (THPS), an environmentally friendly biocide (Xu et al. 2012), could be used as a metabolic uncoupler to reduce sludge production in wastewater treatment. However, the cumulative reductions of waste-activated sludge in laboratory-scale system (28 L) and pilot system $\left(10 \mathrm{~m}^{3}\right)$ were only $22.5 \%$ (Guo et al. 2014b) and 30.8-31.7\% (Xiao et al. 2016), respectively, which were lower than most results when other metabolic uncouplers were used (Fang et al. 2015; Feng et al. 2014; Guo et al. 2013). In addition, an anae robic-anoxic-oxic (A2O) process was used in previous studies (Guo et al. 2014b; Xiao et al. 2016), whereas in most studies with other metabolic uncouplers, activated sludge process (Chen et al. 2002; Rho et al. 2007; Ye and Li, 2005), sequence batch reactors (Feng et al. 2013; Feng et al. 2014; Zheng et al. 2008), or batch experiments (Fang et al. 2015; Ye et al. 2003;) were used. Both of whether the different sludge reductions between THPS and other metabolic uncouplers are caused by their characteristics or by experimental processes and whether the sludge reduction mechanisms of THPS are similar to those of other metabolic uncouplers remains unclear. Additionally, compared to activated sludge process, sequence batch reactor and batch experiment, A2O process is a more wildly used in wastewater treatment plant. For example, in the WWTPs of China, A2O process is the first popular with a ratio of $31 \%$, and sequence batch reactor account for $10 \%$ (Zhang et al. 2016). Furthermore, A2O process can be combined with other process (like membrane bioreactor, MBR) (Banu et al. 2009) and favour the growth of phosphorous-accumulating organisms and and are responsible for phosphorus removal (Raj et al. 2013). So, in order to promote the application of metabolic uncouplers in actual wastewater treatment process, it is more significant to study the effects of metabolic uncouplers in A2O process than the others.

Although, compared with other metabolic uncouplers, THPS presents some advantages in its characteristics, such as environmental friendliness, water solubility, biodegradable, and no residual toxicity (Guo et al. 2013; Xu et al. 2012), it is not clear whether the effects of THPS on sludge reduction system is comparable with other commonly used metabolic uncouplers. So, in order to promote the development and application of sludge reduction technology with metabolic uncoupler, the object of this study was to evaluate the sludge reduction of THPS and other commonly used metabolic uncouplers under similar condition in the laboratoryscale A2O process. Two commonly used metabolic uncouplers, TCS and DCP, were used in the test. Their effects on sludge reduction, wastewater treatment efficiencies, part sludge characteristics, and possible sludge reduction mechanisms were discussed.

\section{Material and methods}

\subsection{Wastewater characteristics}

The wastewater used in the test was obtained from a residential area in Beijing, China. The characteristics of the wastewater are summarized in Table 1.

\subsection{A20 systems and their operations}

Four laboratory-scale A2O systems, which were the same as those used in a previous study (Xiao et al. 2016), were used in the test. The volumes for each part of the A2O systems were as follows: anaerobic tanks, $4 \mathrm{~L}$; anoxic tanks, $4 \mathrm{~L}$; oxic tanks, $16 \mathrm{~L}$; and settlement tanks, $4 \mathrm{~L}$. The anaerobic tanks and anoxic tanks were mixed with mechanical stirring (namely stirring with motor), and the oxic tanks were aerated to maintain the dissolved oxygen (DO) levels. The hydraulic retention time (HRT) and DO of the former three tanks for the four systems are $2 \mathrm{~h}$ and $<0.1 \mathrm{mg} / \mathrm{L}$ (anaerobic tanks), $2 \mathrm{~h}$ and $0.1-0.2 \mathrm{mg} / \mathrm{L}$ (anoxic tanks), and $8 \mathrm{~h}$ and 1.5$3 \mathrm{mg} / \mathrm{L}$ (oxic tanks), respectively, as designed according to Chinese standards. The internal recycling ratio (mixing liquor recycling) and external recycling ratio (sludge recycling) for the four systems were $100 \%$ and $200 \%$, respectively. The sludge concentrations in oxic tanks were controlled at $2-4 \mathrm{~g} / \mathrm{L}$ by regularly discharging sludge from oxic tanks and the sludge retention time four systems were about $10 \mathrm{~d}$. The test was conducted at room temperature (20$28^{\circ} \mathrm{C}$ ).

The four systems were first run for one month, during which the systems reached a steady state, then the metabolic uncouplers were added. The three metabolic uncouplers (TCS, DCP, and THPS) were added continuously into the oxic tanks of the three A2O systems, respectively, and the remaining system without metabolic uncouplers was used as control. The doses of metabolic uncouplers were $1.6 \mathrm{mg} / \mathrm{h}$ (TCS), $40.0 \mathrm{mg} / \mathrm{h}$ (DCP), and $7.0 \mathrm{mg} / \mathrm{h}$ (THPS), respectively, as selected according to previous studies (Chen et al. 2002; Chen et al. 2006; Xiao et al. 2016).

\subsection{Analysis}

The influent, effluent, and mixed sludge in oxic tanks were regularly sampled in the test. The water quality parameters, including soluble and total COD (SCOD and TCOD, respectively), $\mathrm{NH}_{4}^{+}-\mathrm{N}$, total nitrogen (TN), total phosphorous (TP), $\mathrm{pH}$, and SS, of the influent and effluent were analyzed. Mixed sludge characteristics, including sludge concentration (mixed liquor suspended solids [MLSS] and mixed liquor volatile suspended solids [MLVSS]), and sludge volume index (SVI) were analyzed. SCOD and TCOD were determined by a COD meter (DR2800, HACH Co., USA). Samples were filtered through a $0.45 \mu \mathrm{m}$ membrane prior to determining SCOD. $\mathrm{pH}$ was measured by using a pH meter (Sartorius PB-10, Germany). Dissolved oxygen (DO) was measured by an online DO meter (3310, WTW Co., Germany). Other parameters were analyzed by Standard methods (APHA, 1998).

The electronic transport system (ETS) activities and specific ATPs of activated sludge samples in the four systems were measured using the methods of Feng et al. (2014). The 2,3,5triphenyltetrazolium chloride ETC (TTC-ETS) activity was used in the test. The extracellular polymeric substances (EPS) content of activated sludge samples were extracted by using a cation exchange resin (Dowex Marathon C) technique described by Guo et al. (2014a). The polysaccharide (PS) content of the extracted EPS was determined by phenol-sulfuric acid method with glucose

Table 1

Characteristics of wastewater used in the test.

\begin{tabular}{lll}
\hline Parameter & Range & Mean \\
\hline $\mathrm{pH}$ & $7.56-8.43$ & 7.87 \\
$\mathrm{COD}(\mathrm{mg} / \mathrm{L})$ & $64-452$ & 172 \\
$\mathrm{SS}(\mathrm{mg} / \mathrm{L})$ & $16-551$ & 195 \\
$\mathrm{NH}_{4}^{+}-\mathrm{N}(\mathrm{mg} / \mathrm{L})$ & $24.41-59.54$ & 46.11 \\
$\mathrm{TN}(\mathrm{mg} / \mathrm{L})$ & $37.6-92.4$ & 56.93 \\
$\mathrm{TP}(\mathrm{mg} / \mathrm{L})$ & $3.03-9.45$ & 5.86 \\
\hline
\end{tabular}


as a standard (Dubois et al. 1956), and the protein (PN) content was determined by the Lowry method with bovine serum albumin as a standard (Lowry et al. 1951). Activated sludge samples were centrifuged for $15 \mathrm{~min}$ with $6000 \mathrm{rpm}$, and supernatants were filtered using a $0.45 \mu \mathrm{m}$ membrane prior to measurement of protein and DNA content. The protein content of sludge supernatants was also determined by the Lowry method (1951), and DNA content was determined by diphenylamine colorimetric method using fish sperm DNA and sodium salt as standards (Sun et al., 1999).

\subsection{Data analysis}

Average results and standard errors were reported based on triplicates for each analysis or determination. Statistical significance was tested by analysis of variance (ANOVA), and means were separated using Tukey's honestly significant difference (HSD) tests with a threshold P-value of 0.05 declared significant. All data were analyzed by using SPSS 19.0 for Windows (IBM, USA).

\section{Results and discussion}

\subsection{Sludge reduction}

The four systems were operated for 85 days, and their accumulative sludge productions in the test are summarized in Fig. 1-A. At the end of the test, the total accumulative sludge productions of the four systems were $538.2 \mathrm{~g}$ (control system), $330.5 \mathrm{~g}$ (TCS system), $304.4 \mathrm{~g}$ (DCP system), and $326.7 \mathrm{~g}$ (THPS system), respectively. The total sludge reduction by adding three metabolic uncouplers at the end of the test were calculated as $38.6 \%$ (TCS system), 43.4\% (DCP system), and 39.3\% (THPS system). The observed growth yields $\left(Y_{\mathrm{obs}}\right)$ of sludge for the four systems in the test were also calculated, and the results are summarized in Fig. 1-B. The $Y_{\text {obs }}$ of sludge for the four systems were changed in $0.330-0.444 \mathrm{mg}$ $\mathrm{MLSS} / \mathrm{mg}$ removed COD (mean $=0.370 \mathrm{mg} \mathrm{MLSS} / \mathrm{mg}$ removed COD, control system), 0.252-0.433 mg MLSS/mg removed COD
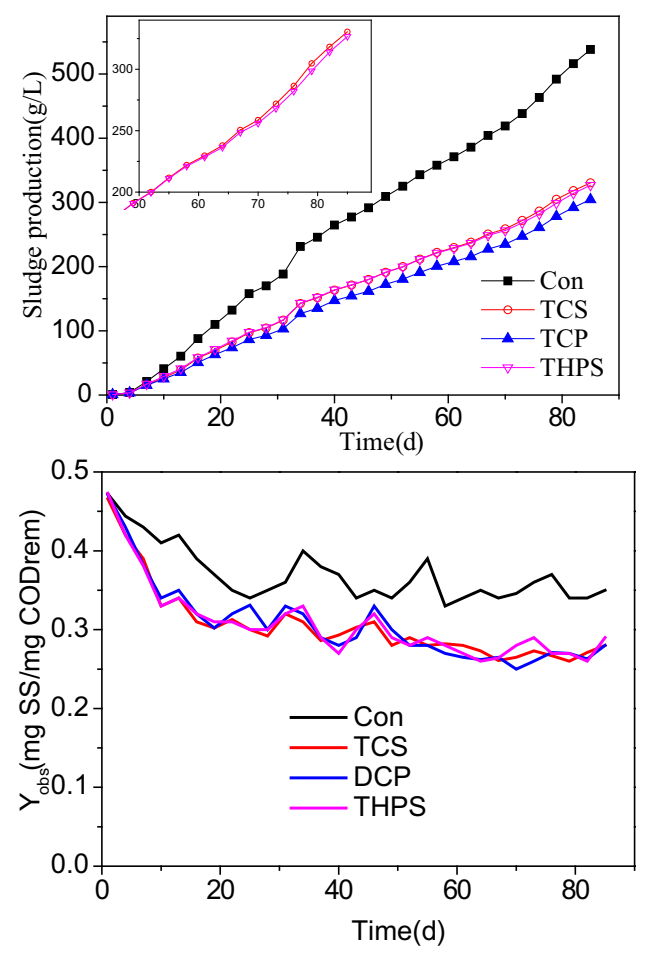

Fig. 1. Accumulative production of sludge and variations in sludge $Y_{\text {obs. }}$.
( mean $=0.307 \mathrm{mg}$ MLSS $/ \mathrm{mg}$ removed COD, TCS system), 0.261$0.419 \mathrm{mg}$ MLSS $/ \mathrm{mg}$ removed COD (mean $=0.305 \mathrm{mg} \mathrm{MLSS} / \mathrm{mg}$ removed COD, DCP system), and $0.263-0.422 \mathrm{mg}$ MLSS $/ \mathrm{mg}$ removed COD (mean $=0.307 \mathrm{mg}$ MLSS $/ \mathrm{mg}$ removed COD, THPS system). The mean reductions of sludge $Y_{\text {obs }}$ for the three metabolic uncouplers were 16.98\% (TCS), $17.55 \%$ (DCP), and $17.04 \%$ (THPS), respectively. The reductions of sludge and sludge $Y_{\mathrm{obs}}$ in the test were similar to those in our previous studies but lower than most results of other studies. For example, Guo et al. (2014b) got $14.7 \%$ of sludge $Y_{\text {obs }}$ reduction with THPS; while Yang et al. (2003) got $86.9 \%$ of excess sludge reduction with mchlorophenol and Feng et al. (2014) and Tian et al. (2013) got $42.7 \%$ and $40 \%$ of sludge $Y_{\text {obs }}$ reduction with TCS and 2,6dichlorophenol, respectively. As mentioned in the introduction, the differences may be due to the different wastewater quality and wastewater treatment system. The differences of sludge production and sludge $Y_{\text {obs }}$ reduction among the three metabolic uncoupers were statistical analyzed with Tukey's HSD tests and the p-values are summarized in Table 2. The p-value of Tukey's HSD tests between excess sludge reductions of TCS an THPS added systems were higher than 0.05 . Meanwhile, the p-values of Tukey's HSD tests among $Y_{\text {obs }}$ reductions of three metabolic uncouplers added systems were all higher than 0.05 . The statistical analysis results suggest that the effects of TCS and THPS on sludge production were similar and those of three metabolic uncouplers on sludge $Y_{\text {obs }}$ were similar.

\subsection{Wastewater treatment efficiency}

As a metabolic uncoupler for sludge reduction in biological wastewater treatment, the effect of metabolic uncoupler on wastewater treatment efficiency should be absent or slight (Guo et al. 2013). Therefore, the effects of the three metabolic uncouplers on the wastewater treatment efficiencies of A2O systems were studied, and four common water-quality parameters (COD, $\mathrm{NH}_{4}^{+}-\mathrm{N}, \mathrm{TN}$, and TP) were detected in the test (Table 3).

For the four parameters, the addition of three metabolic uncouplers resulted in the decrease of COD removal by 5.0\% (TCS), $3.2 \%$ (DCP), and 3.8\% (THPS); $\mathrm{NH}_{4}^{+} \mathrm{N}$ removal by $1.1 \%$ (TCS), $2.8 \%$ (DCP), and 1.8\% (THPS); TN removal by 7.7\% (TCS), 8.6\% (DCP), and $8.7 \%$ (THPS); and TP removal by $2.8 \%$ (TCS), $3.2 \%$ (DCP), and $3.2 \%$ (THPS). The results show that the addition of THPS exerted the maximal decrease on TN and TP removal and the minimal decrease on COD removal. The results indicate that the addition of three metabolic uncouplers could slightly lower wastewater treatment efficiencies. Previous studies had reported similar results (Guo et al. 2014; Zheng et al. 2008). For example, Zheng et al. (2008) found that the addition of TCP resulted in $8 \%$ decrease of COD removal and Guo et al. 2014 found removal of COD and $\mathrm{NH}_{4}^{+}-\mathrm{N}$ decreased about $6.8 \%$ and $2.1 \%$ by adding THPS, respectively. Like previous studies, the effects of three uncoupers on wastewater treatment efficiencies in this study were slight and the effluent of three uncouplers added processes still could meet the discharge standard. The statistical analysis results suggested that the differences among the three metabolic uncouplers were very little because their p-values of Tukey's HSD tests were all higher than 0.05 (Table 2).

\subsection{Settlement ability}

Settlement ability of activated sludge is crucial in the A2O processes. Therefore, to study the effects of the three metabolic uncouplers on the settlement ability of activated sludge in A2O processes, the activated sludge SVI, a settlement ability index, for the four systems, was detected and the results are summarized in Fig. 2. 
Table 2

p-values of Tukey's HSD tests between three metabolic uncouplers.

\begin{tabular}{|c|c|c|c|c|c|c|c|c|}
\hline \multirow[t]{2}{*}{ Uncoupler } & \multicolumn{2}{|c|}{$\begin{array}{l}\text { Sludge production } \\
\text { reduction }\end{array}$} & \multicolumn{2}{|c|}{$\mathrm{Y}_{\mathrm{obs}}$ reduction } & \multicolumn{2}{|c|}{$\begin{array}{l}\text { Wastewater treatment } \\
\text { efficiencies }\end{array}$} & \multicolumn{2}{|l|}{ SVI } \\
\hline & DCP & THPS & DCP & THPS & DCP & THPS & DCP & THPS \\
\hline TCS & 0.001 & 0.72 & 0.7 & 0.62 & $0.18-0.77$ & $0.08-0.46$ & 1 & 0.52 \\
\hline DCP & - & 0.001 & - & 0.99 & - & $0.26-0.98$ & - & 0.6 \\
\hline
\end{tabular}

Table 3

Wastewater treatment efficiencies of the four systems.

\begin{tabular}{|c|c|c|c|c|c|}
\hline Item & & Control & TCS & DCP & THPS \\
\hline \multirow[t]{3}{*}{ COD removal (\%) } & Minimum & 82.3 & 68.1 & 76.0 & 77.5 \\
\hline & Maximum & 95.7 & 95.7 & 95.8 & 91.7 \\
\hline & Mean & 90.2 & 85.2 & 87.0 & 86.4 \\
\hline \multirow[t]{3}{*}{$\mathrm{NH}_{4}^{+}-\mathrm{N}$ removal (\%) } & Minimum & 82.3 & 68.1 & 76.0 & 77.5 \\
\hline & Maximum & 99.8 & 99.4 & 99.4 & 99.3 \\
\hline & Mean & 98.9 & 97.8 & 96.1 & 97.1 \\
\hline \multirow[t]{3}{*}{ TN removal (\%) } & Minimum & 45.4 & 38.6 & 39.6 & 38.9 \\
\hline & Maximum & 96.0 & 93.6 & 93.0 & 92.4 \\
\hline & Mean & 76.9 & 69.2 & 68.3 & 68.2 \\
\hline \multirow[t]{3}{*}{ TP removal (\%) } & Minimum & 52.2 & 47.5 & 49.0 & 49.0 \\
\hline & Maximum & 65.8 & 61.8 & 64.1 & 63.8 \\
\hline & Mean & 58.9 & 56.1 & 55.7 & 55.7 \\
\hline
\end{tabular}

The SVI of activated sludge for four systems were changed in 52-211 mL/g MLSS. In 0-28 days, the activated sludge SVIs for the four systems were similar, changing in $58 \mathrm{~mL} / \mathrm{g}-139 \mathrm{~mL} / \mathrm{g}$ MLSS. The settleability of activated sludge in four systems were all changed from good to fair (Jenkins and Wanner 2014). On the 19th day, the activated sludge of the four systems exhibited slight bulking because of the change in influent, and the activated sludge SVIs changed to 124 (control), 143 (TCS), 139 (DCP), and $160 \mathrm{~mL} / \mathrm{g}$ MLSS (THPS). After the 28th day, the differences among the activated sludge SVIs for the four systems appeared: the activated sludge SVIs for the four systems changed in 52-128 mL/g MLSS (control), 116-174 mL/g MLSS (TCS), 112-178 mL/g MLSS (DCP), and $113-211 \mathrm{~mL} / \mathrm{g}$ MLSS (THPS). The average SVIs of sludge for the four systems were $88.0 \pm 2.4 \mathrm{~mL} / \mathrm{g}$ MLSS (control), $149.5 \pm 3.8 \mathrm{~mL} / \mathrm{g}$ MLSS (TCS), $150.2 \pm 0.5 \mathrm{~mL} / \mathrm{g}$ MLSS (DCP), and $158.9 \pm 4.3 \mathrm{~mL} / \mathrm{g}$ MLSS (THPS). The SVI of activated sludge in three metabolic uncouplers added systems were higher than that in control system and three metabolic uncouplers increased the average SVIs of sludge about $69.9 \%$ (TCS), 70.7\% (DCP) and 80.6\% (THPS), respectively. Compared to the activated sludge in control system,

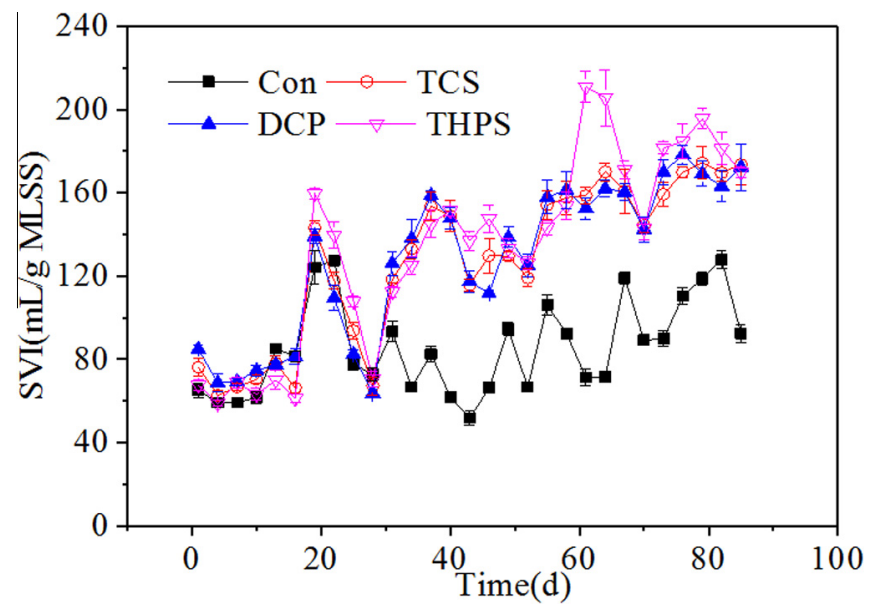

Fig. 2. Variations in SVI of activated sludge. the activated sludge in the metabolic uncouplers added systems exhibited slight bulking in stage of 28-85 d. Additionally, the activated sludge SVI for THPS-added system were over $200 \mathrm{~mL} / \mathrm{g}$ MLSS and the activated sludge were bulking only at 61st $\mathrm{d}$ and 64th $\mathrm{d}$. Besides the stage (61st d-64th d), the settlement abilities of the activated sludge for all systems were fair because their SVIs were all lower than $200 \mathrm{~mL} / \mathrm{g}$ MLSS (Jenkins and Wanner 2014) and the increased of sludge SVI did not affect the wastewater treatment efficiencies. Several previous studies also reported slight bulking during sludge reduction with metabolic uncouplers (Guo et al 2014b; Zheng et al. 2007; Zheng et al. 2008). For example, Zheng et al. (2007) found that $2 \mathrm{mg} / \mathrm{L} \mathrm{2,4,6-trichlorophenol} \mathrm{resulted} \mathrm{in}$ the increase of sludge SVI in 20 L SBR. The activated sludge SVI for the three metabolic uncouplers added systems were similar because their p-value of Tukey's HSD tests were higher than 0.05 (Table 2), which suggests that the effects of three metabolic uncouplers on the activated sludge SVI were also similar.

\subsection{Sludge reduction mechanisms}

The following four mechanisms are typically involved in sludge reduction: lysis-cryptic growth, uncoupled metabolism, maintenance metabolism, and biological predation. As biological predation did not occur in this study, the other three mechanisms of sludge reduction were discussed. The variation in ETS activity, SATP, EPS contents of activated sludge, and proteins and DNA contents in the supernatants of activated sludge were used as indicators to determine whether metabolic uncoupling, maintenance metabolism, and lysis-cryptic growth occurred in the test, respectively (Feng et al. 2014). Above parameters of activated sludge were measured on the 5th, 20th, 42nd, 65th, and 84th days and the results are summarized in Figures 3-5.

Fig. 3 summarizes the variation in TTC-ETS and SATP of activated sludge in the four systems. The TTC-ETS of activated sludge for the four systems changed in 139-148 $\mu \mathrm{g} / \mathrm{mg}$ SS.h (mean $=144 \mu \mathrm{g} /$ $\mathrm{mg} \mathrm{SS} \mathrm{h}$, control), 95-139 $\mu \mathrm{g} / \mathrm{mg} \mathrm{SS} \mathrm{h} \quad$ (mean $=109 \mu \mathrm{g} / \mathrm{mg} \mathrm{SS} \mathrm{h}$, TCS), $84-145 \mu \mathrm{g} / \mathrm{mg} \mathrm{SS} \mathrm{h}$ (mean $=102 \mu \mathrm{g} / \mathrm{mg}$ SS$\cdot \mathrm{h}, \mathrm{DCP}$ ), and 105$138 \mu \mathrm{g} / \mathrm{mg}$ SS h (mean $=115 \mu \mathrm{g} / \mathrm{mg}$ SS $\mathrm{h}$, THPS). The TTC-ETS of activated sludge in the four systems were similar on the 5th day, and those in the three metabolic uncoupler added systems were 
lower than those in the control system on other days. The TTC-ETS of activated sludge in the control system were the highest, followed by those in the THPS system and those in DCP system were the lowest. The mean TTC-ETS inhibitory rates of three uncoupers were 24.3\% (TCS), 29.2\% (DCP) and 20.1\% (THPS), respectively. The mean TTCETS inhibitory rates were lower than $33.14 \%$ gotten by Feng et al. (2014) in studying possible causes of excess sludge reduction adding TCS in sequence batch reactors, which may be due the different influent and wastewater treatment process. The SATP of activated sludge for the four systems changed in 69-74 RLU L/mg SS (mean = 71.2 RLU L/mg SS, control), 53-68 RLU L/mg SS (mean = 5 8.0 RLU L/mg SS, TCS), 45-72 RLU L/mg SS (mean = 53.8 RLU L/ $\mathrm{mg} \mathrm{SS}$, DCP), and 56-68 RLU L/mg SS (mean $=60.0 \mathrm{RLU} \mathrm{L} / \mathrm{mg} \mathrm{SS}$, THPS). Similar to TTC-ETS, the SATPs of activated sludge in the control system were also the highest, followed by those in the THPS system and those in DCP system were the lowest. The results show the addition of three metabolic uncouplers reduced the SATP of activated sludge and the mean SATP reduced rate of three metabolic uncouplers were $18.5 \%$ (TCS), $24.4 \%$ (DCP) and $15.7 \%$ (THPS), respectively. The results indicate that adding the three metabolic uncouplers reduced the TTC-ETS and SATP of activated sludge, which suggests that metabolic uncoupling occurred in all three metabolic uncouplers added systems since the ETS activity variation may demonstrate the effects of metabolic uncoupling and the ATP variation directly suggest the occurrence of metabolic uncoupling in microorganisms (Feng et al. 2014).

The EPS content of activated sludge for the four systems changed in $20.38-21.35 \mathrm{mg} / \mathrm{g}$ SS (mean $=20.74 \mathrm{mg} / \mathrm{g} \mathrm{SS}$, control), $20.48-23.92 \mathrm{mg} / \mathrm{g} \mathrm{SS} \quad($ mean $=22.68 \mathrm{mg} / \mathrm{g} \mathrm{SS}, \quad$ TCS $), \quad 20.37-$ $23.19 \mathrm{mg} / \mathrm{g}$ SS $($ mean $=22.01 \mathrm{mg} / \mathrm{g} \mathrm{SS}, \mathrm{DCP}$ ), and $20.58-25.00 \mathrm{mg} /$ $\mathrm{g}$ SS (mean $=23.28 \mathrm{mg} / \mathrm{g} \mathrm{SS}$, THPS) (Fig. 4). The results show the mean of EPS content in the THPS-added system was the highest,
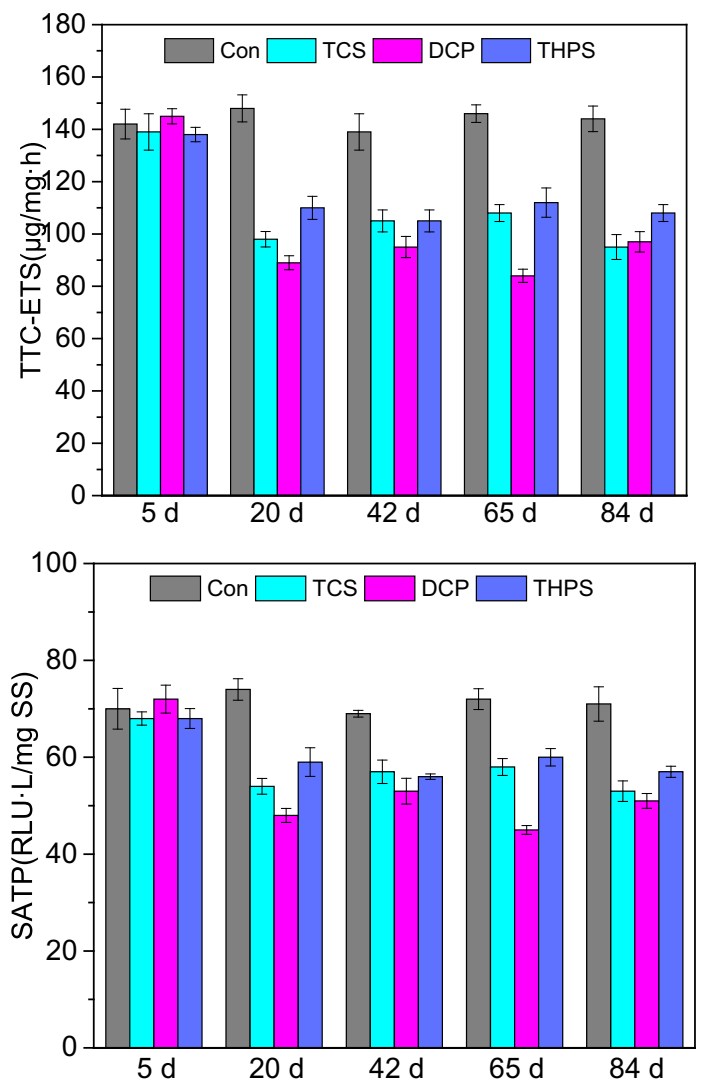

Fig. 3. Variations in TTC-ETS and SATP of activated sludge.

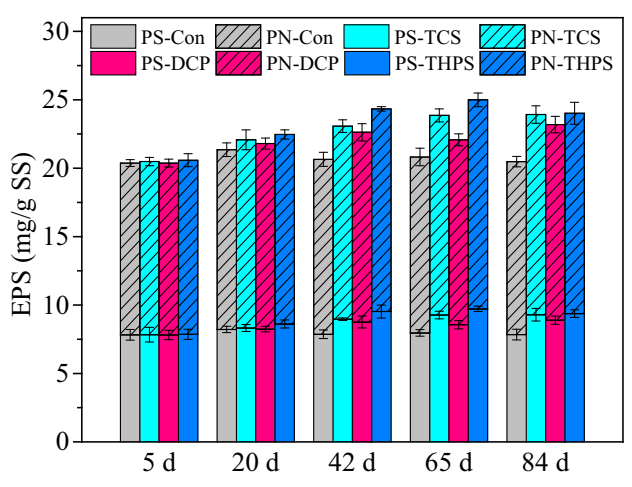

Fig. 4. Variations in EPS content of activated sludge.
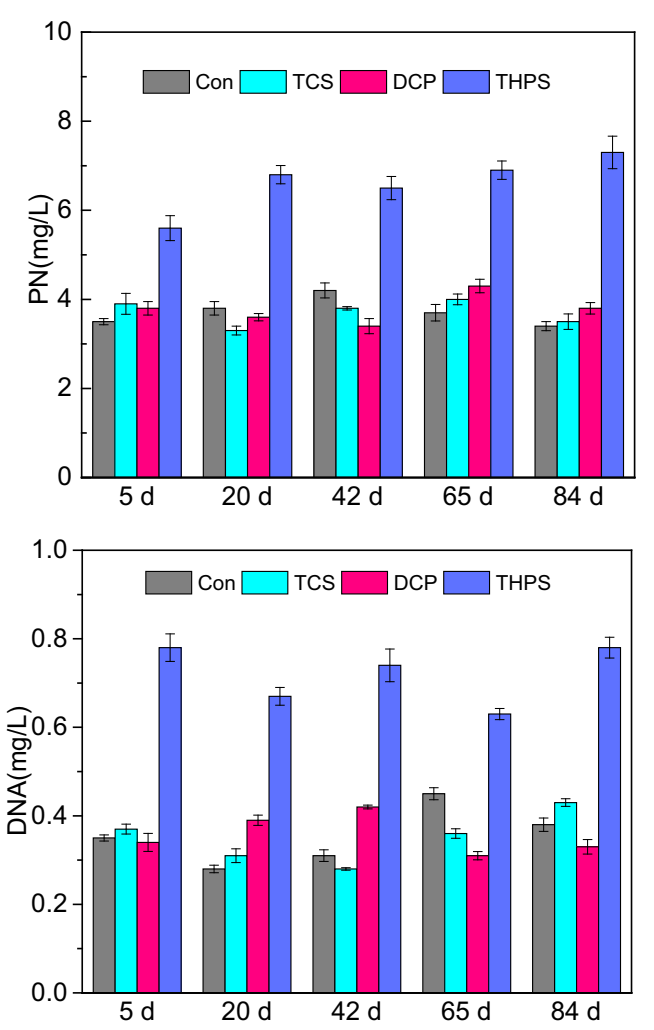

Fig. 5. Protein and DNA contents in supernatants of activated sludge.

whereas that in the control system was the lowest. The results suggested that the addition of three metabolic uncouplers could increase the EPS content of activated sludge. The increased EPS content of activated sludge in metabolic uncouplers added systems suggest that the addition of three metabolic uncouplers causes sludge microbes to generate additional EPS to resist toxicities of metabolic uncouplers and become accustomed to the uncouplerexistent environment (Feng et al. 2014). In the three metabolic uncouplers added systems, the sludge microbes need more energy to resist the infection of metabolic uncouplers (Feng et al. 2014). These results indicate that maintenance metabolism also occurred in the three metabolic uncouplers added systems. Additionally, the increase of EPS content would increase the sludge SVI and deteriorate the sludge settleability (Sheng et al. 2010), which is consistent with the results in Fig. 2.

As the content proteins and DNA in the supernatant of activated sludge can be used to represent the lysis of sludge microbial cells 
in the wastewater treatment (Feng et al. 2014; Guo et al. 2014a), the differences in protein and DNA contents in the supernatants of the activated sludge among the four systems were detected to determine the existence of microbial lysis (Fig. 5). In the test, the protein contents in the supernatants of activated sludge in the four systems were changed in $3.4-4.2 \mathrm{mg} / \mathrm{L}$ (Control), $3.3-4.0 \mathrm{mg} / \mathrm{L}$ (TCS), 3.4-4.3 mg/L (DCP) and 5.7-7.3 mg/L (THPS). Meanwhile, the DNA contents were changed in $0.28-0.46 \mathrm{mg} / \mathrm{L}$ (Control), $0.28-0.42 \mathrm{mg} / \mathrm{L}$ (TCS), $0.31-0.42 \mathrm{mg} / \mathrm{L}$ (DCP) and $0.63-0.78 \mathrm{mg} / \mathrm{L}$ (THPS) (Fig. 5). The protein and DNA contents in the THPS-added system were both higher than those in the other three systems, and those in the other three systems were similar because their p-values of Tukey's HSD tests were higher than 0.05 (data were not shown). These results suggest that the microbial lysis of sludge in the THPS-added systems exceeds those in the other three systems and that in other three systems were similar. The finding is reasonable because THPS is a biocide, which can kill microbes (Struchtemeyer et al. 2012; Xu et al. 2012). Additionally, Feng et al. (2014) also found that TCS did not affect the DNA content in effluent. The above results indicate that lysis-cryptic growth occurred in the THPS-added systems and did not occur in the TCS- and DCP-added systems.

\section{Conclusion}

The sludge reductions resulting from the three metabolic uncouplers (TCS, DCP, and THPS) were evaluated in the laboratory-scale anaerobic-anoxic-oxic process. The three metabolic uncouplers could reduce sludge production (38.6-43.4\%) and sludge $Y_{\text {obs }}$ (16.98-17.55\%). Meanwhile, adding the three uncouplers would slightly reduce the wastewater treatment efficiencies and settlement ability of activated sludge. No evident differences among the three uncouplers were observed in sludge reduction and effects on wastewater treatment efficiencies. The sludge reduction mechanism involves metabolic uncoupling and maintenance metabolism in the TCS- and DCP-added systems. However, in the THPS-added system, lysis-cryptic growth is also involved.

\section{Acknowledgement}

The authors are grateful for the financial support provided by the National Natural Science Foundation of China (No. 51378492).

\section{References}

APHA, 1998. Standard Methods for the Examination of Water and Wastewater. American Public Health Association, Washington DC, USA.

Aragóna, C., Quirogab, J.M., Coello, M.D., 2009. Comparison of four chemical uncouplers for excess sludge reduction. Environ. Technol. 30, 707-714.

Banu, J.R., Uan, D.K., Yeom, I.-T., 2009. Nutrient removal in an A2O-MBR reactor with sludge reduction. Bioresour. Technol. 100, 3820-3824.

Chen, G.H., Mo, H.K., Liu, Y., 2002. Utilization of a metabolic uncoupler, 3,3',4',5tetrachlorosalicylanilide (TCS) to reduce sludge growth in activated sludge culture. Water Res. 36, 2077-2083.

Chen, G.W., Yu, H.Q., Xi, P.G., 2006. Influence of 2,4-dinitrophenol on the characteristics of activated sludge in batch reactors. Bioresour. Technol. 98, 729-733.

Chen, G.W., Yu, H.Q., Xi, P.G., Xu, D.Q., 2008. Modeling the yield of activated sludge in the presence of 2,4-dinitrophenol. Biochem. Eng. J. 40, 150-156.

Cho, S.-K., Shin, H.-S., Kim, D.-H., 2012. Waste activated sludge hydrolysis during ultrasonication: two-step disintegration. Bioresour. Technol. 121, 480-483.

Dubois, M., Gilles, K.A., Hamilton, J.K., Rebers, P.A., Smith, F., 1956. Colorimetric method for determination of sugars and related substances. Anal. Chem. 28, 350-356.

Fang, F., Hu, H.-L., Qin, M.-M., Xue, Z.-X., Cao, J.-S., Hu, Z.-R., 2015. Effects of metabolic uncouplers on excess sludge reduction and microbial products of activated sludge. Bioresour. Technol. 185, 1-6.
Feng, X.-C., Guo, W.-Q., Chen, C., Yang, S.-S., Jin, W.-B., Ren, N.-Q., Zheng, H.-S., Du, J.S., Liu, B., 2013. Treatability study of $3,3^{\prime}, 4^{\prime}, 5$-tetrachlorosalicylanilide (TCS) combined with 2,4,6-trichlorophenol (TCP) to reduce excess sludge production in a sequence batch reactor. Bioresour. Technol. 143, 642-646.

Feng, X.-C., Guo, W.-Q., Yang, S.-S., Zheng, H.-S., Du, J.-S., Wu, Q.-L., Ren, N.-Q., 2014 Possible causes of excess sludge reduction adding metabolic uncoupler $3,3^{\prime}, 4^{\prime}, 5$-tetrachlorosalicylanilide (TCS), in sequence batch reactors. Bioresour Technol. 173, 96-103.

Guo, W.Q., Yang, S.S., Xiang, W.S., Wang, X.J., Ren, N.Q., 2013. Minimization of excess sludge production by in-situ activated sludge treatment processes - a comprehensive review. Biotechnol. Adv. 31 (8), 1386-1396.

Guo, X.S., Liu, J.X., Xiao, B.Y., 2014a. Evaluation of the damage of cell wall and cell membrane for various extracellular polymeric substance extractions of activated sludge. J. Biotechnol. 188, 130-135.

Guo, X.S., Yang, J.M., Liang, Y., Liu, J.X., Xiao, B.Y., 2014b. Evaluation of sludge reduction by an environmentally friendly chemical uncoupler in a pilot-scale anaerobic-anoxic-oxic process. Bioprocess Biosyst. Eng. 37, 553-560.

Jenkins, D., Wanner, J., 2014. Activated Sludge - 100 Years and Counting. IWA Publishing.

Li, M.Y., Xiao, B.Y., Wang, X., Liu, J.X., 2015. Consequences of sludge composition on combustion performance derived from thermogravimetry analysis. Waste Manage. 35, 141-147.

Lowry, O.H., Rosebrough, N.J., Farr, A.L., Randall, R.J., 1951. Protein measurement with the Folin phenol reagent. J. Biol. Chem. 1993, 265-275.

Niu, T.H., Zhou, Z., Shen, X.L., Qian, W.M., Jiang, L.-M., Pan, W., Zhou, J.J., 2016. Effects of dissolved oxygen on performance and microbial community structure in a micro-aerobic hydrolysis sludge in situ reduction process. Water Res. 90, 369377.

Paul, E., Debellefontaine, H., 2007. Reduction of excess sludge produced by biological treatment processes: effect of ozonation on biomass and on sludge. Ozone Sci. Eng. 29, 415-427.

Raj, S.E., Banu, J.R., Kaliappan, S., Yeom, I.-T., Kumar, S.A., 2013. Effects of sidestream, low temperature phosphorus recovery on the performance of anaerobic/anoxic/oxic systems integrated with sludge pretreatment. Bioresour. Technol. 140, 376-384.

Rho, S., Nam, G.-N., Shin, J.Y., Jahng, D., 2007. Effect of 3,3',4',5-tetrachloro salicylanilide on reduction of excess sludge and nitrogen removal in biological wastewater treatment process. J. Microbiol. Biotech. 17 (7), 1183-1190.

Semblante, G.U., Hai, F.I., Bustamante, H., Guevara, N., Price, W.E., Nghiem, L.D., 2016. Biosolid reduction by the oxic-settling-anoxic process: impact of sludge interchange rate. Bioresour. Technol. 210, 167-173.

Sheng, G.P., Yu, H.Q., Li, X.Y., 2010. Extracellular polymeric substances (EPS) of microbial aggregates in biological wastewater treatment systems: A review. Biotechnol. Adv. 28, 882-894.

Strand, S.E., Harem, G.N., Stensel, H.D., 1999. Activated sludge yield reduction using chemical uncouplers. Water Environ. Res. 71 (4), 454-458.

Struchtemeyer, C.G., Morrison, M.D., Elshahed, M.S., 2012. A critical assessment of the efficacy of biocides used during the hydraulic fracturing process in shale natural gas wells. Int. Biodeter. Biodegr. 71, 15-21.

Sun, Y., Clinkenbeard, K.D., Clarke, C., Cudd, L., Highlander, S.K., Dabo, S.M., 1999. Pasteurella haemolytica leukotoxin induced apoptosis of bovine lymphocytes involves DNA fragmentation. Vet. Microbiol. 65, 153-166.

Tian, Y., Zhang, J., Wu, D., Li, X.P., Cui, Y.N., 2013. Distribution variation of a metabolic uncoupler, 2,6-dichlorophenol (2,6-DCP) in long-term sludge culture and their effects on sludge reduction and biological inhibition. Water Res. 47, 279-288.

Xiao, B.Y., Li, H.C., Yan, H., Guo, X.S., 2016. Evaluation of the sludge reduction effectiveness of a metabolic uncoupler-tetrakis (hydroxymethyl) phosphonium sulfate in anaerobic/anoxic/oxic process. Desalin. Water Treat. 57, 5772-5780.

Xu, D., Li, Y., Gu, T., 2012. A synergistic D-tyrosine and tetrakis (hydroxymethyl) phosphonium sulfate biocide combination for the mitigation of an SRB biofilm. World J. Microbiol. Biot. 28, 3067-3074.

Yang, X.-F., Xie, M.-L., Liu, Y., 2003. Metabolic uncouplers reduce excess sludge production in an activated sludge process. Proc. Biochem. 38, 1373-1377.

Ye, F.X., Li, Y., 2005. Reduction of excess sludge production by $3,3,4^{\prime}, 5$ tetrachlorosalicylanilide in an activated sludge process. Appl. Microbiol. Biot. 67, 269-274.

Ye, F.X., Shen, D.S., Li, Y., 2003. Reduction in excess sludge production by addition of chemical uncouplers in activated sludge batch cultures. J. Appl. Microbiol. 95, 781-786.

Zhang, Q.H., Yang, W.N., Ngo, H.H., Guo, W.S., Jin, P.K., Dzakpasu, M., Yang, S.J., Wang, Q., Wang, X.C., Ao, D., 2016. Current status of urban wastewater treatment plants in China. Environ. Int. 92-93, 11-22.

Zheng, G.H., Chen, Z.Y., Wang, L., Qian, Y.F., Zhou, Q., 2007. Treatment of municipal wastewater with the sequence batch reactor under uncoupling metabolic conditions. J. Environ. Sci. Heal. A. 42, 2059-2064.

Zheng, G.H., Li, M.N., Wang, L., Chen, Z.Y., Qian, Y.F., Zhou, Q., 2008. Feasibility of 2,4,6-trichlorophenol and malonic acid as metabolic uncoupler for sludge reduction in the sequence batch reactor for treating organic wastewater. Appl. Biochem. Biotechnol. 144, 101-109. 